\title{
'I Need the Sea and the Sea Needs Me': Symbiotic coastal policy narratives for human wellbeing and sustainability in the UK
}

\author{
Catherine Kelly \\ University of Greenwich, Department of Marketing, Events and Tourism, Queen Anne Court, \\ Park Row, Greenwich, London SE10 9LS, UK
}

\section{Highlights}

-

A collaborative approach is called for, citing core human wellbeing and coastal sustainability policy values.

This research advocates a bottom up approach to marine custodianship based on learning and wellbeing benefits.

-

Primary research showed increased subjective wellbeing levels for participants in a coastal programme case study.

-

School group visits to the beach reported improved learning, wellbeing and future sustainability behaviour intentions.

The creation of Coastal Learning Zones is called for, as sites of reciprocal sustainability, education and wellbeing needs.

Human emotions and nature-connection with the sea are central to people/place relationships at the coast.

\section{Abstract}

The human desire to be near coastal waters is an innate aspect of both human settlement choices and leisure behaviour. Emerging research agendas in the general field of 'wellbeing' focus on outdoor wellness, advocating the health and psychological benefits of nature. This presence of and engagement with coastal landscapes and water, or 'Blue Space' is a positive indicator in wellbeing, learning, outdoor activity and pro-environmental behaviour amongst the wider population. Simultaneously, the global marine policy agenda continues its commitment to coastal conservation and sustainability. To date, wellbeing, and marine policy agendas have mostly been segregated. This paper advocates a combined, integrative approach to policy that incorporates symbiotic sustainability-wellbeing narratives, proofing, and 
monitoring for the long term successful management of the coastal environment. Starting with the proposition that the sea needs humans, and humans need the sea, this research argues that valuing the coast and sea through its learning and wellbeing benefits can encourage pro-environmental and pro-sustainability attitudes. Little has been done to explore how the wellbeing benefits and emotional meaning people have felt through interacting with coastal environments can be harnessed for greater engagement and education around marine conservation. It challenges the mainstream discourse on marine conservation which often relies on people valuing the sea intrinsically from an altruistic and moral perspective. Primary research is presented on UK coastal learning and outdoor wellbeing programmes. Framing the coast as a therapeutic landscape with potential for simultaneously meeting human needs and marine needs, allows for inclusive policy decision making.

\section{Keywords}

Coastal sustainability

Wellbeing

Nature

Bluespace

Symbiosis

Outdoor wellbeing

Emotional geography

Children

Beach

Education

Place-attachment

Therapeutic landscapes 